Психология. Журнал Высшей школы экономики.

2018. T. 15. № 3. C. 447-463. DOI: 10.17323/1813-8918-2018-3-447-463

\title{
СЕКСИЗМ ПО ОТНОШЕНИЮ К ЖЕНЩИНАМ: АДАПТАЦИЯ ШКАЛЫ АМБИВАЛЕНТНОГО СЕКСИЗМА (П. ГЛИКА И С. ФИСК) НА РУССКИЙ ЯЗЫК
}

\author{
Е.Р. АГАДУЛЛИНА
}

${ }^{a}$ Национальный исследовательский университет «Высшая икола экономики», 101000, Россия, Москва, ул. Мясницкая, д. 20

\begin{abstract}
Резюме
В статье представлена адаптация на русский язык методики П. Глика и С. Фиск по оценке амбивалентного сексизма в отношении женщин. Данный инструментарий направлен на измерения не только враждебного (тенденция негативно оценивать женцин, нарушающци традиционные гендерные роли), но и доброжелательного (тенденция позитивно оценивать женцин, соответствующих традиционным гендерным ожиданиям) сексизма. В апробации методики приняли участие 1624 жителя России. Полная версия методики продемонстрировала удовлетворительное соответствие эмпирическим данным, в связи с болышим количеством ковариаций между суждениями методики. Исходя из выявленных ковариаций суждений, была сформирована ее короткая версия. Короткая версия методики, включающая 12 суждений ( 6 в шкале враждебного сексизма и 6 в шкале доброжелательного сексизма), продемонстрировала хорошее соответствие эмпирическим данным $\left(\chi^{2}=332.147^{*}, \mathrm{df}=53\right.$, RMSEA $=0.057$, CFI $=0.960$, TLI $=0.950)$. Мультигрупповой анализ продемонстрировал полную структурную и факторную эквивалентность при использовании короткой версии методики на выборке мужчин и женщин, а также гетеросексуалов и людей с негетеросексуальной идентификацией. Выявлены социально-демографические различия в результатах, полученных при помощи короткой версии методики. Мужчины и гетеросексуалы в большей степени, чем женщины и негетеросексуалы, демонстрируют враждебный и доброжелательный сексизм; люди старше 30 лет в большей степени проявляют доброжелательный сексизм, чем более молодые респонденты. В целом представленный вариант короткой версии методики демонстрирует хорошие психометрические показатели и может быть использован для дальнейших исследований как надежный и устойчивый инструментарий.
\end{abstract}

Ключевые слова: сексизм, враждебный сексизм, доброжелательный сексизм, методика.

Традиционно сексизм рассматривается исследователями как негативное или враждебное отношение к представителям гендерных групп (преимушественно к женщинам). В 1996 г. Питер Глик и Сьюзен Фиск предложили пересмотреть такое понимание сексизма и разработали теорию амбивалентного сексизма, которая предполагает, что установки к гендерным группам амбивалентны, т.е. включают в себя одновременно как враждебное, так и доброжелательное отношение (Glick, Fiske, 1996, 2001). 
Амбивалентность отношений к гендерным группам обусловлена двумя фактами. Во-первых, в современном обществе мужчины все еще обладают большим статусом и властью, что приводит к возникновению и поддержанию враждебного (временами даже агрессивного) отношения к женщинам, которые своим поведением оспаривают господство мужчин и ставят под сомнение патриархальный статус-кво. Во-вторых, мужчины и женшины взаимозависимы и нуждаются друг в друге как в биологическом (рождение детей), так и в социальном плане (выполняют взаимодополняющие социальные роли), что делает невозможным только враждебное отношение к женщинам и приводит к возникновению по отношению к ним субъективно доброжелательных, но патерналистских отношений.

В результате враждебный сексизм описывает тенденцию негативно оценивать женщин, нарушающих традиционные гендерные роли и ожидания (например, женщин, нацеленных на карьеру, а не на рождение детей и заботу о муже), а доброжелательный сексизм - позитивно оценивать женщин, соответствующих традиционным гендерным ожиданиям (например, заботливая мать и домохозяйка) (Gaunt, 2013; Glick et al., 2015). При этом доброжелательный сексизм только на первый взгляд кажется позитивной установкой, так как восприятие женщин как беззащитных субъектов, нуждаюшихся в постоянной рыцарской заботе со стороны мужчин, только подчеркивает зависимость женщин от мужчин в обществе (Viki et al., 2003).

По мнению П. Глика с соавт., враждебный и доброжелательный сексизм являются взаимосвязанными и взаимодополняющими установками, которые оправдывают и рационализируют гендерное неравенство (Glick et al., 2000, 2004). Так, доброжелательный сексизм как патерналистская идеология связан с оправданием существующей социальной иерархии (Jost et al., 2004), авторитарными установками, которые предполагают, что все люди должны придерживаться общепринятых социальных норм и ценностей (Christopher, Mull, 2006), с готовностью ограничивать других людей в правах, оправдывая это заботой о них (например, запрещая женщинам выполнять определенные виды работы, ссылаясь на заботу об их здоровье, в то время как на мужчин такой запрет не распространяется) (Sutton et al., 2011). В целом доброжелательный сексизм способствует принятию женщинами традиционных социальных ролей, уменьшает ценность внешнего признания, мотивации к профессиональному развитию и тем самым легитимирует низкий статус женщин в обществе (Mosso et al., 2013).

Со своей стороны враждебный сексизм в отношении женшин связан с ориентапией на социальное доминирование (Christopher, Mull, 2006; Mosso et al., 2013) и предсказывает восприятие гендерной иерархии как стабильной и неизменной (Glick, Whitehead, 2010). Кроме того, враждебный сексизм связан с большей толерантностью к сексуальным домогательствам (Russell, Trigg, 2004) и насилию, проявляемому в отношении членов семьи (например, женщин) (Glick et al., 2002), поддержанием классических мифов об изнасиловании, в рамках которых вина за случившееся возлагается на женщину (Chapleau et al., 2007) и принятием стереотипов о «красоте» (идеале красоты) (Forbes et al., 2007). 


\section{Методика оценки амбивалентного сексизма}

Первый вариант методики оценки амбивалентного сексизма в отношении женщин был представлен П. Гликом и С. Фиск в 1996 г. (Glick, Fiske, 1996). Он включает 22 суждения, по 11 на каждую шкалу. Шкала враждебного сексизма содержит утверждения, описывающие женщин как стремящихся подчинить себе мужчин или отобрать у них власть (например, «Женщины, выступающие за равноправие, пытаются получить больше власти, чем у мужчин» и т.д.). Шкала доброжелательного сексизма включает утверждения, описывающие женщин как добрых, прекрасных, но несамостоятельных людей, нуждающихся в постоянной заботе и защите (например, «Женщины должны быть окружены заботой и защитой мужчин» и т.д.). По мнению авторов, доброжелательный сексизм не является однородным явлением, поэтому данная шкала включает три субшкалы: «Защитный патернализм» содержит суждения о том, что женщин надо защищать и обеспечивать в обмен на то, что они не будут претендовать на высокое положение в обществе (например, «Мужчина должен быть готов пожертвовать собственным благополучием для того, чтобы финансово обеспечить женщину»); «Взаимодополняемость гендерных различий» содержит представления о том, что положительные черты, приписываемые женщинам, компенсируют то, чего стереотипно не хватает мужчинам (например, «Многие женщины обладают такой нравственной чистотой, которая присуща лишь немногим мужчинам»); «Гетеросексуальная близость» включает в себя суждения о том, что мужчина стремится к близости с женщиной и без наличия таких отношений он не может чувствовать себя полноценно (например, «Без женской любви даже очень успешный мужчина не может считаться полноценной личностью»).

Методика оценки амбивалентного сексизма является популярным исследовательским инструментом, который активно адаптируется на разные языки мира - норвежский (Bendixen, Kennair, 2017), итальянский (Rollero et al., 2014), немецкий (Eckes, Six-Materna, 1999), кастильский и испанский (Garaigordobil, Aliri, 2013; Ibabe et al., 2016), португальский (Costa et al., 2015; Goncalves et al., 2015), французский (Dardenne et al., 2006) и турецкий (SakalliUgurlu, 2002). Несмотря на значимость и актуальность изучения различных проявлений сексизма в современном обществе, в настоящий момент отсутствует качественная адаптация методики амбивалентного сексизма для русскоязычной выборки. Целью данной статьи является адаптация методики оценки амбивалентного сексизма по отношению к женщинам (как наиболее традиционным объектам сексистского поведения) и проверка ее психометрических свойств.

\section{Выборка}

В исследовании приняли участие 1624 жителя России ${ }^{1}$ (78.1\% женщин $(\mathrm{n}=1275), 23$ респондента не указали свой пол), $\mathrm{M}_{\text {вораст }}=22.22, \mathrm{SD}_{\text {вораст }}=6.82$.

\footnotetext{
${ }^{1}$ Автор благодарит Марьяну Балезину и Влада Кривощекова за помощь в сборе эмпириче-
} 
708 человек определили свою сексуальную ориентацию как гетеросексуальную, 32 - гомосексуальную, 206 - бисексуальную, 106 - другую, 572 человек пропустили ответ на этот вопрос.

\section{Методики}

Амбивалентный сексизм в отношении женщин оценивался при помощи методики П. Глика и С. Фиск, переведенной на русский язык тремя переводчиками независимо друг от друга, далее в результате сравнения трех вариантов был составлен окончательный список суждений. Методика включает в себя 22 суждения, из которых 11 описывают враждебное отношение к женщинам (например, «За стремлением к равенству на самом деле скрывается желание многих женщин получить преимущества перед мужчинами (например, при приеме на работу)»,) 11 - доброжелательное отношение (например, «Женщины должны быть окружены заботой и защитой мужчин») (см. приложение 1). Каждое суждение необходимо оценить по шкале от 0 (полностью не согласен) до 5 (полностью согласен) $(\alpha=0.91$ и 0.88 для враждебного и доброжелательного сексизма соответственно).

Для проверки внешней валидности шкалы использовались следующие методики.

Правый авторитаризм измерялся при помощи однофакторной шкалы Боба Альтемейера (Altemeyer, 2006), адаптированной на русский язык. Шкала включает 22 суждения, каждое из которых необходимо оценить по шкале от 1 (полностью не согласен) до 9 (полностью согласен) $(\alpha=0.94)$.

Оправдание социальной системы оценивалось при помощи трех суждений: «Существующая в России система социальных, политических и экономических отношений между разными гендерными группами справедлива, в ней каждая группа получает то, что заслуживает / Правильная, в ней каждая группа на своем месте / Идеальна для российских граждан» (Thompson, Jost, 2000). Каждое суждение необходимо оценить с помощью шкалы от 1 (полностью не согласен) до 7 (полностью согласен) $(\alpha=0.79)$.

Для оценки стремления к социальному доминированию использовалась короткая версия «Social dominance orientation scale (SDO)» (Pratto et al., 1994), адаптированная на русский язык. Шкала включает 10 суждений, каждое из которых необходимо оценить с помощью шкалы от 1 (полностью не согласен) до 7 (полностью согласен) $(\alpha=0.90)$.

\section{Результаты}

\section{Структура шкаль амбивалентного сексизма по отношению к женщинам}

Для проверки структуры шкалы амбивалентного сексизма был проведен конфирматорный факторный анализ в программе Mplus7. Оригинальная модель с 22 суждениями (по 11 суждений на каждую шкалу) продемонстрировала низкое ских данных. 
соответствие исходным данным и рекомендованным нормам (Hu, Bentler, 1999) (см. таблицу 1).

Анализ индексов модификации показал наличие ковариаций ошибок между различными суждениями внутри шкал (см. таблицу 2). Выявленные ковариации ошибок имеют логичные основания. Так, суждения $8,22,19$, по мнению Глика и Фиск, объединяются в субшкалу доброжелательного сексизма - «Взаимодополняемость гендерных различий». Обоснованно ожидать, что эти суждения могут быть сильно связаны между собой, так как они направлены на оценку одной сущности. Суждения 6 и 13 относятся к субшкале «Гетеросексуальная близость», а суждения 7 и 21 входят в шкалу враждебного сексизма. Кроме того, семантически и содержательно они сформулированы схожим образом, что может определять их сильную ковариацию. То же самое касается суждений 4 и 5, каждое из которых описывает женщин как чрезмерно обидчивых по сравнению с мужчинами.

Так как выявленные ковариации имеют логичное обоснование, они были внесены в модель, и для модифицированной модели были рассчитаны основные индексы соответствия. Как видно из таблицы 1, модифицированная модель значительно лучше соответствует исходным данным, тем не менее ее сложно назвать удовлетворительной.

\section{Короткая версия шкаль амбивалентного сексизма}

В связи с тем, что полная версия шкалы не демонстрирует хорошего соответствия исходным данным, была создана короткая версия шкалы. Для этого

Таблица 1

Показатели соответствия конфирматорных моделей

\begin{tabular}{|l|c|c|c|c|c|c|c|}
\hline \multicolumn{1}{|c|}{ Модель } & $\boldsymbol{x}^{2}$ & $\mathbf{d f}$ & $\begin{array}{c}\text { RMSEA } \\
{[\mathbf{9 0 \%} \text { CI }]}\end{array}$ & SRMR & CFI & TLI & AIC \\
\hline $\begin{array}{l}\text { Полная модель (22 } \\
\text { суждения- } \\
2 \text { фактора) }\end{array}$ & $2181.628^{*}$ & 208 & $\begin{array}{c}0.077 \\
{[0.074 ; 0.080]}\end{array}$ & 0.050 & 0.858 & 0.833 & 115704 \\
\hline $\begin{array}{l}\text { Полная модель (22 } \\
\text { суждения - 2 фактора, } \\
\text { модиф. 6 ковариаций) }\end{array}$ & $1266.258^{*}$ & 202 & $\begin{array}{c}0.057 \\
{[0.054 ; 0.060]}\end{array}$ & 0.046 & 0.919 & 0.907 & 114549 \\
\hline $\begin{array}{l}\text { Сокращенная модель } \\
\text { (12 суждений - } \\
\text { 2 фактора) }\end{array}$ & $332.147^{*}$ & 53 & $\begin{array}{c}0.057 \\
{[0.051 ; 0.063]}\end{array}$ & 0.034 & 0.960 & 0.950 & 62181 \\
\hline
\end{tabular}

Примечание. $\chi^{2}$ - критерий хи-квадрат; $\mathrm{df}$ - число степеней свободы; RMSEA - среднеквадратическая ошибка оценки; CFI - показатель сравнительного соответствия; TLI - ненормированный показатель соответствия; SRMR - стандартизированный корень среднеквадратического остатка; AIC - информационный критерий Акайке; * $-p<0.001$. 
Ковариации ошибок суждений

\begin{tabular}{|c|c|c|c|c|}
\hline № & $\begin{array}{c}\text { Формулировка } \\
\text { суждения }\end{array}$ & № & Формулировка суждения & $\begin{array}{c}\text { Значение ковариации } \\
\text { ошибок }\left(\chi^{2}\right)\end{array}$ \\
\hline 7 & $\begin{array}{l}\text { Женщины, выступающие } \\
\text { за равноправие, } \\
\text { пытаются получить } \\
\text { больше власти, чем у } \\
\text { мужчин }\end{array}$ & 21 & $\begin{array}{l}\text { Женшины, выступающие за } \\
\text { равноправие, выдвигают по } \\
\text { отношению к мужчинам } \\
\text { необоснованные требования }\end{array}$ & 286.820 \\
\hline 19 & $\begin{array}{l}\text { Поступки женщин более } \\
\text { моральны, чем поступки } \\
\text { мужчин }\end{array}$ & 8 & $\begin{array}{l}\text { Многие женщины обладают } \\
\text { такой нравственной } \\
\text { чистотой, которая присуца } \\
\text { лишь немногим мужчинам }\end{array}$ & 206.636 \\
\hline 19 & $\begin{array}{l}\text { Поступки женщин более } \\
\text { моральны, чем поступки } \\
\text { мужчин }\end{array}$ & 22 & $\begin{array}{l}\text { В отличие от мужчин } \\
\text { женщины обладают более } \\
\text { развитым чувством } \\
\text { прекрасного и хорошим } \\
\text { вкусом }\end{array}$ & 165.647 \\
\hline 4 & $\begin{array}{l}\text { Большинство женщин } \\
\text { воспринимают невинные } \\
\text { замечания или действия } \\
\text { как оскорбительные }\end{array}$ & 5 & $\begin{array}{l}\text { Женщин, по сравнению с } \\
\text { мужчинами, слишком легко } \\
\text { обидеть }\end{array}$ & 104.183 \\
\hline 6 & $\begin{array}{l}\text { Многие женщины не } \\
\text { могут быть по- } \\
\text { настоящему счастливы } \\
\text { без романтических } \\
\text { отношений с мужчинами }\end{array}$ & 13 & $\begin{array}{l}\text { Без женщины жизнь } \\
\text { мужчины нельзя назвать } \\
\text { полноценной }\end{array}$ & 95.406 \\
\hline 22 & $\begin{array}{l}\text { В отличие от мужчин } \\
\text { женщины обладают } \\
\text { более развитым чувством } \\
\text { прекрасного и хорошим } \\
\text { вкусом }\end{array}$ & 8 & $\begin{array}{l}\text { Многие женщины обладают } \\
\text { такой нравственной } \\
\text { чистотой, которая присуща } \\
\text { лишь немногим мужчинам }\end{array}$ & 74.399 \\
\hline
\end{tabular}

из каждой пары ковариируюших суждений было удалено суждение с меньшей стандартизованной факторной нагрузкой. Далее для выравнивания размера обеих шкал из оставшихся суждений последовательно удалялись суждения с меньшими нагрузками. В результате сокрашенный вариант методики включил 12 суждений (по 6 на каждую шкалу) (см. приложение 1). Для сокращенного варианта методики был проведен конфирматорный факторный анализ, результаты которого показывают, что модель, содержашая 12 суждений, объединенных в два фактора, демонстрирует хорошее соответствие эмпирическим данным. Как видно из таблицы 1, показатели CFI и TLI превышают 
пороговое значение 0.93, значение RMSEA ниже 0.08, а значение SRMR ниже 0.06. Распределение суждений по шкалам и стандартизованные факторные нагрузки представлены на рисунке 1.

В таблице 3 представлена описательная статистика суждений, входящих в короткий вариант методики амбивалентного сексизма. Как видно из представленных данных, большинство суждений демонстрирует правую асимметрию, что свидетельствует о склонности респондентов в своих ответах скорее не соглашаться с данными суждениями. Бимодальное распределение у большинства суждений (положительная асимметрия при отрицательном эксцессе) свидетельствует о том, что методика описывает два различных способа поведения. В целом распределение ответов на большинство суждений незначительно отклоняется от нормального, при этом наличие суждений с явно выраженной асимметрией и эксцессом может указывать на неоднородность ответов респондентов на эти суждения.

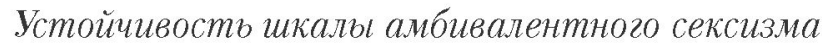

Для проверки воспроизводимости и устойчивости структуры короткой версии шкалы и факторных нагрузок суждений был проведен мультигрупповой факторный анализ, для которого респонденты были разделены на подгруппы.

Модель амбивалентного сексизма

Рисунок 1 ( $\mathrm{BC}$ - враждебный сексизм, ДС - доброжелательный сексизм)

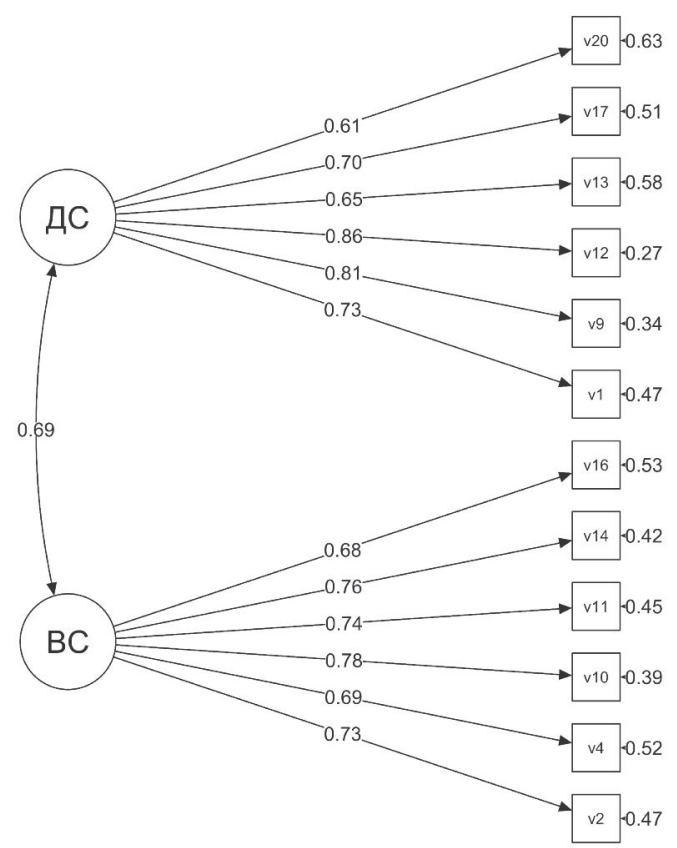


Таблица 3

Описательная статистика по суждениям методики и корреляции пунктов с общим показателем

\begin{tabular}{|c|c|c|c|c|c|c|c|}
\hline № & Формулировки суждений & $\mathbf{M}$ & SD & Med & A & Э & $\mathbf{r}$ \\
\hline$\underset{(1)}{1 \_ \text {ДС }}$ & $\begin{array}{l}\text { Без женской любви даже очень } \\
\text { успешный мужчина не может } \\
\text { считаться полноценной личностью }\end{array}$ & 1.75 & 1.56 & 1 & 0.574 & -0.800 & 0.612 \\
\hline$\underset{(2)}{2-B C}$ & $\begin{array}{l}\text { За стремлением к равенству на самом } \\
\text { деле скрывается желание многих } \\
\text { женщин получить преимущества } \\
\text { перед мужчинами (например, при } \\
\text { приеме на работу) }\end{array}$ & 2.28 & 1.60 & 2 & 0.034 & -1.158 & 0.637 \\
\hline $\begin{array}{l}3 \mathrm{BC} \\
(4)\end{array}$ & $\begin{array}{l}\text { Большинство женщин воспринимают } \\
\text { невинные замечания или действия } \\
\text { как оскорбительные }\end{array}$ & 2.53 & 1.44 & 3 & 0.03 & -0.888 & 0.565 \\
\hline 4_ДС & $\begin{array}{l}\text { Женщины должны быть окружены } \\
\text { заботой и защитой мужчин }\end{array}$ & 2.83 & 1.56 & 3 & -0.333 & -0.932 & 0.715 \\
\hline $\begin{array}{c}5 \_B C \\
(10)\end{array}$ & $\begin{array}{l}\text { Большинство женщин не могут в } \\
\text { полной мере оценить все, что } \\
\text { мужчины делают для них }\end{array}$ & 2.45 & 1.52 & 3 & 0.030 & -1.031 & 0.700 \\
\hline$\frac{6 \_B C}{(11)}$ & $\begin{array}{l}\text { Женщины стремятся заполучить } \\
\text { власть, устанавливая контроль над } \\
\text { мужчинами }\end{array}$ & 2.03 & 1.47 & 2 & 0.330 & -0.832 & 0.641 \\
\hline$\underset{(12)}{7 \text { ДС }}$ & $\begin{array}{l}\text { У каждого мужчины должна быть } \\
\text { женщина, которую он обожает }\end{array}$ & 2.33 & 1.70 & 2 & 0.135 & -1.248 & 0.735 \\
\hline$\underset{(13)}{8 \_ \text {ДС }}$ & $\begin{array}{l}\text { Без женщины жизнь мужчины } \\
\text { нельзя назвать полноценной }\end{array}$ & 2.22 & 1.68 & 2 & 0.237 & -1.194 & 0.553 \\
\hline $\begin{array}{l}9 \_B C \\
(14)\end{array}$ & $\begin{array}{l}\text { Женшины преувеличивают } \\
\text { проблемы, с которыми они } \\
\text { сталкиваются на работе }\end{array}$ & 2.22 & 1,46 & 2 & 0.148 & -0.906 & 0.659 \\
\hline $\begin{array}{c}10-\mathrm{BC} \\
(16)\end{array}$ & $\begin{array}{l}\text { Когда женщины проигрывают } \\
\text { мужчинам в честном соревновании, } \\
\text { они, как правило, жалуются на } \\
\text { дискриминацию }\end{array}$ & 2,11 & 1.46 & 2 & 0.300 & -0.837 & 0.556 \\
\hline 11_ДС & $\begin{array}{l}\text { Мужчины должны возводить } \\
\text { настоящих женщин на пьедестал }\end{array}$ & 1.82 & 1.50 & 2 & 0.490 & -0.742 & 0.619 \\
\hline $\begin{array}{c}12 \_ \text {ДС } \\
(20)\end{array}$ & $\begin{array}{l}\text { Мужчина должен быть готов } \\
\text { пожертвовать собственным } \\
\text { благополучием для того, чтобы } \\
\text { финансово обеспечить женцину }\end{array}$ & 1.49 & 1.31 & 1 & 0.692 & -0.203 & 0.527 \\
\hline
\end{tabular}

Примелание. M - среднее, SD - стандартное отклонение, Med - медиана, A - асимметрия, $Э$ - эксцесс, $r$ - корреляция с суммой остальных пунктов, ДС - доброжелательньй сексизм, ВС - враждебный сексизм. В скобках указан номер суждения из полного варианта методики. 
В одном случае проводилось сравнение оценок по шкалам между мужчинами и женщинами, в другом - между людьми с разной сексуальной самоидентификацией (гетеросексуалы, бисексуалы и люди, обладающие другой негетеросексуальной идентичностью). В рамках мультигруппового факторного анализа оценивались три уровня соответствия моделей. Первый уровень - это конфигурационная (структурная) инвариантность (configural invariance), которая указывает на то, что в разных группах респондентов шкалы включают в себя одни и те же суждения. Второй уровень - метрическая инвариантность (metric invariance). Она указывает на то, что факторные нагрузки суждений схожи для разных групп оценки. Третий уровень - скалярная инвариантность (scalar invariance) - свидетельствует о том, что нагрузки разных суждений вносят эквивалентный вклад в латентную переменную. В таблице 4 представлены результаты мультигруппового факторного анализа, которые свидетельствуют о том, что шкала демонстрирует полную инвариантность (на всех трех уровнях) при сравнении групп мужчин и женщин, т.е. можно утверждать, что модель амбивалентного сексизма демонстрирует устойчивую факторную структуру.

Для групп людей с разной сексуальной идентификацией шкала также демонстрирует приемлемые показатели соответствия, которые незначительно ухудшаются при оценке скалярной инвариантности.

\section{Внешняя валидность икаль амбивалентного сексизма}

Для проверки внешней валидности русскоязычной шкалы амбивалентного сексизма был проведен корреляционный анализ показателей враждебного и доброжелательного сексизма со склонностью к социальному доминированию, авторитарным установкам и с тенденцией оправдывать существующую социальную систему. Ранее было показано, что каждая из этих переменных значимо связана с проявлением амбивалентного сексизма, так как в совокупности они способствуют оправданию и поддержанию гендерного неравенства в обществе. Результаты, представленные в таблице 5, наглядно демонстрируют выраженные положительные корреляции между всеми исследуемыми переменными, что свидетельствует о внешней валидности предложенной пккалы.

\section{Социально-демографические различия в проявлении амбивалентного сексизма}

Согласно результатам, представленным в таблице 6 , и мужчины и женщины в большей степени демонстрируют враждебный, чем доброжелательный сексизм. При этом уровень враждебного и доброжелательного сексизма у мужчин выше, чем у женщин. Эти результаты согласуются с данными, полученными в предыдущих исследованиях (Bendixen, Kennair, 2017; Glick et al., 2000; Zawisza et al., 2015). Гетеросексуалы в большей степени склонны разделять враждебный и доброжелательный сексизм по сравнению с людьми, имеющими другую сексуальную самоидентификацию. 
Результаты мультигруппового факторного анализа

\begin{tabular}{|c|c|c|c|c|c|c|c|c|c|c|c|c|}
\hline Групाы & Модель & $x^{2}$ & df & $\begin{array}{c}\text { RMSEA } \\
{[90 \% \mathrm{CI}]}\end{array}$ & SRMR & CFI & TLI & AIC & BIC & $\Delta \chi^{2}$ & $\Delta \mathbf{d f}$ & $\triangle \mathrm{CFI}$ \\
\hline \multirow{3}{*}{$\begin{array}{c}\text { Гендерные } \\
\text { группы } \\
\text { (мужчины, } \\
\text { женщины) }\end{array}$} & $\begin{array}{l}\text { Конфигурационная } \\
\text { инвариантность }\end{array}$ & $374.620^{*}$ & 106 & $\begin{array}{c}0.056 \\
{[0.051 ; 0.062]}\end{array}$ & 0.036 & 0.962 & 0.953 & 61524 & 30324 & - & - & - \\
\hline & $\begin{array}{l}\text { Метрическая } \\
\text { инвариантность }\end{array}$ & $425.743^{*}$ & 116 & $\begin{array}{c}0.058 \\
{[0.053 ; 0.063]}\end{array}$ & 0.045 & 0.956 & 0.950 & 61557 & 30245 & $51.123^{*}$ & 10 & 0.006 \\
\hline & $\begin{array}{l}\text { Скалярная } \\
\text { инвариантность }\end{array}$ & $461.772^{*}$ & 126 & $\begin{array}{c}0.058 \\
{[0.053 ; 0.063]}\end{array}$ & 0.047 & 0.953 & 0.950 & 61573 & 30213 & $36.029^{*}$ & 10 & 0.003 \\
\hline \multirow{3}{*}{$\begin{array}{c}\text { Сексуальная } \\
\text { ориентация } \\
\text { (гетеро- } \\
\text { сексуалы, } \\
\text { бисексуалы, } \\
\text { другая) }\end{array}$} & $\begin{array}{l}\text { Конфигурационная } \\
\text { инвариантность }\end{array}$ & $404.189^{*}$ & 159 & $\begin{array}{c}0.068 \\
{[0.061 ; 0.075]}\end{array}$ & 0.049 & 0.940 & 0.925 & 38123 & 30335 & - & - & - \\
\hline & $\begin{array}{l}\text { Метрическая } \\
\text { инвариантность }\end{array}$ & $453.191^{*}$ & 179 & $\begin{array}{c}0.068 \\
{[0.061 ; 0.074]}\end{array}$ & 0.063 & 0.933 & 0.925 & 38139 & 30268 & $49.002^{*}$ & 20 & 0.007 \\
\hline & $\begin{array}{l}\text { Скалярная } \\
\text { инвариантность }\end{array}$ & $520.902^{*}$ & 199 & $\begin{array}{c}0.069 \\
{[0.063 ; 0.076]}\end{array}$ & 0.067 & 0.921 & 0.921 & 38171 & 30228 & $67.711^{*}$ & 20 & 0.012 \\
\hline
\end{tabular}

Примечание. $\chi^{2}$ - критерий хи-квадрат; $\mathrm{df}$ - число степеней свободы; CFI - показатель сравнительного соответствия; TLI - ненормированный показатель соответствия; RMSEA - среднеквадратическая ошибка оценки; SRMR - стандартизированный корень среднеквадратического остатка; AIC - информационный критерий Акайке.

* $-p<0.001$. 


\section{Интеркорреляции и описательные статистики пкал}

\begin{tabular}{|l|c|c|c|c|c|c|c|}
\hline \multicolumn{1}{|c|}{ Переменные } & $\mathbf{M}$ & $\mathbf{S D}$ & $\boldsymbol{\alpha}$ & $\mathbf{1}$ & $\mathbf{2}$ & $\mathbf{3}$ & $\mathbf{4}$ \\
\hline 1. Враждебньй сексизм & 2.29 & 1.17 & 0.87 & - & & & \\
\hline $\begin{array}{l}\text { 2. Доброжелательный } \\
\text { сексизм }\end{array}$ & 2.07 & 1.21 & 0.87 & $0.603^{* *}$ & - & & \\
\hline 3. Оправдание системы & 2.46 & 1.00 & 0.79 & $0.355^{* *}$ & $0.400^{* *}$ & - & \\
\hline $\begin{array}{l}\text { 4. Ориентация на } \\
\text { социальное доминирование }\end{array}$ & 2.85 & 1.13 & 0.90 & $0.484^{* *}$ & $0.486^{* *}$ & $0.310^{*}$ & - \\
\hline 5. Правый авторитаризм & 2.35 & 1.25 & 0.94 & $0.581^{* *}$ & $0.600^{* *}$ & $0.456^{* *}$ & $0.657^{* *}$ \\
\hline
\end{tabular}

Примечапие. Приводятся коэффициенты корреляции Спирмена. ${ }^{*} p<0.05,{ }^{*}{ }^{*} p<0.01$.

Таблица 6

Социально-демографические различия в проявлении амбивалентного сексизма

\begin{tabular}{|c|c|c|c|c|c|c|c|c|}
\hline & $\mathbf{M}$ & SD & $\mathbf{M}$ & SD & $\mathbf{M}$ & SD & & \\
\hline & \multicolumn{2}{|c|}{$\begin{array}{c}\text { Мужчины } \\
(n=334)\end{array}$} & \multicolumn{2}{|c|}{$\begin{array}{l}\text { Женцины } \\
(n=1275)\end{array}$} & & & $F(3,1621)$ & $\eta^{2}$ \\
\hline $\mathrm{BC}$ & 2.95 & 1.21 & 2.32 & 1.18 & & & $26.952^{*}$ & 0.07 \\
\hline \multirow[t]{2}{*}{ ДС } & 2.62 & 1.28 & 2.15 & 1.21 & & & $13.616^{*}$ & 0.04 \\
\hline & \multicolumn{2}{|c|}{$\begin{array}{c}\text { Гетеросексуаль } \\
\quad(n=708)\end{array}$} & \multicolumn{2}{|c|}{$\begin{array}{c}\text { Бисексуальь } \\
(n=206)\end{array}$} & \multicolumn{2}{|c|}{$\begin{array}{c}\text { Другая негетеро- } \\
\text { сексуальная ориен- } \\
\text { тация }(n=106)\end{array}$} & $\mathrm{F}(2,1011)$ & $\begin{array}{l}\text { Попарные } \\
\text { сравнения }\end{array}$ \\
\hline $\mathrm{BC}$ & 2.47 & 1.11 & 1.84 & 1.24 & 1.71 & 1.28 & $36.377^{*}$ & $1>2=3$ \\
\hline \multirow[t]{2}{*}{ ДС } & 2.38 & 1.18 & 1.35 & 0.97 & 1.28 & 1.11 & $93.031^{*}$ & $1>2=3$ \\
\hline & \multicolumn{2}{|c|}{$\begin{array}{l}\text { До } 20 \text { лет } \\
(n=950)\end{array}$} & \multicolumn{2}{|c|}{$\begin{array}{c}\text { Om } 20 \text { 20 } 30 \\
\operatorname{sem}(n=527)\end{array}$} & \multicolumn{2}{|c|}{$\begin{array}{l}\text { Cmapue } 30 \text { rem } \\
(n=147)\end{array}$} & $F(2,1622)$ & \\
\hline $\mathrm{BC}$ & 2.41 & 1.21 & 2.46 & 1.27 & 2.79 & 0.97 & $6.310, p=0.002$ & $1=2<3$ \\
\hline ДС & 2.18 & 1.22 & 2.23 & 1.22 & 2.82 & 1.22 & $17.886^{*}$ & $1=2<3$ \\
\hline
\end{tabular}

Примечание. Для попарных сравнений использовался апостериорный тест Тьюки (Тukey's HSD test); M - среднее, SD - стандартное отклонение; ${ }^{*}-p<0.001$.

Респонденты до 30 лет демонстрируют больше враждебного, чем доброжелательного сексизма, в то время как респонденты после 30 лет в равной степени разделяют враждебное и доброжелательное отношение к женщинам. Важно, что люди после 30 лет продемонстрировали наиболее выраженный 
уровень доброжелательного сексизма по сравнению с более молодыми респондентами.

\section{Обсуждение результатов}

В статье представлена адаптация на русский язык методики оценки амбивалентного сексизма в отношении женщин. Оригинальная версия методики продемонстрировала неудовлетворительное соответствие исходным данным, что было отмечено и при адаптации методики на норвежский язык (Bendixen, Kennair, 2017) и кастильский язык (Garaigordobil, Aliri, 2013).

В статье предложена краткая версия методики оценки амбивалентного сексизма по отношению к женщинам, включающая 12 утверждений, разделенных на две шкалы. Полученные результаты указывают на структурную и внешнюю валидность краткой версии методики, а также свидетельствуют об инвариантности факторной структуры шкалы при сравнении разных выборок. В соответствии с данными, полученными в других странах, оценки по шкалам доброжелательного и враждебного сексизма, полученные на российских респондентах, значимо положительно коррелируют друг с другом и с другими конструктами, поддерживаюшими и оправдывающими гендерное неравенство в обществе (Glick et al., 2004).

Описанные в статье результаты указывают на то, что короткая версия методики оценки амбивалентного сексизма в отношении женщин может быть использована в будущих исследованиях как надежный и устойчивый инструментарий. Изучение сексизма как сложного конструкта, включающего не только враждебное, но и патерналистически доброжелательное отношение к женщинам, позволит исследователям глубже понять природу сексизма и, возможно, сформулировать позитивную программу по сокращению гендерного неравноправия в современном обществе.

Ссылки на зарубежные источники см. в разделе References после анллоязиного блока.

Приложение 1

ІІкала амбивалентного сексизма по отношению к женцинам (полный вариант)

Ниже приводится ряд утверждений, касающихся мужчин и женщин и их отношений в современном обществе. Пожалуйста, укажите, в какой степени вы согласны или не согласны с каждым утверждением, используя следующую шкалу:

0 - Полностью не согласен

1 - Не согласен

2 - Скорее не согласен

3 - Скорее согласен

4 - Согласен

5 - Полностью согласен 
1. Без женской любви даже очень успешный мужчина не может считаться полноценной личностью.

2. За стремлением к «равенству» на самом деле скрывается желание многих женщин получить преимущества перед мужчинами (например, при приеме на работу).

3. Во время катастрофы женщин необходимо спасать раньше мужчин.

4. Большинство женщин воспринимают невинные замечания или действия как оскорбительные.

5. Женщин, по сравнению с мужчинами, слишком легко обидеть.

6. Многие женщины не могут быть по-настоящему счастливы без романтических отношений с мужчинами.

7. Женщины, выступающие за равноправие, пытаются получить больше власти, чем у мужчин.

8. Многие женщины обладают такой нравственной чистотой, которая присуща лишь немногим мужчинам.

9. Женщины должны быть окружены заботой и защитой мужчин.

10. Большинство женщин не могут в полной мере оценить все, что мужчины делают для них.

11. Женщины стремятся заполучить власть, устанавливая контроль над мужчинами.

12. У каждого мужчины должна быть женщина, которую он обожает.

13. Без женщины жизнь мужчины нельзя назвать полноценной.

14. Женщины преувеличивают проблемы, с которыми они сталкиваются на работе.

15. Заполучив мужчину, женщина старается держать его на коротком поводке.

16. Когда женщины проигрывают мужчинам в честном соревновании, они, как правило, жалуются на дискриминацию.

17. Мужчины должны возводить настоящих женщин на пьедестал.

18. Многие женщины наслаждаются тем, что дразнят мужчин, сначала демонстрируя доступность, а затем отвергая мужские ухаживания.

19. Поступки женщин более моральны, чем поступки мужчин.

20. Мужчина должен быть готов пожертвовать собственным благополучием для того, чтобы финансово обеспечить женщину.

21. Женщины, выступающие за равноправие, выдвигают по отношению к мужчинам необоснованные требования.

22. В отличие от мужчин женщины обладают более развитым чувством прекрасного и хорошим вкусом.

Вражіебный сексизм: 2, 4, 5, 7, 10, 11, 14, 15, 16, 18, 21.

Доброжелательный сексизм: 1, 3, 6, 8, 9, 12, 13, 17, 19, 20, 22.

Гетеросексуальная близость: 1, 6, 12, 13

Зациттный патернализм: 3, 9, 17, 20

Взаимодополняемость гендерных различии: $8,19,22$ 


\section{Шкала амбивалентного сексизма по отношению к женщинам (короткий вариант)}

Ниже приводится ряд утверждений, касающихся мужчин и женщин, и их отношений в современном обществе. Пожалуйста, укажите, в какой степени вы согласны или не согласны с каждым утверждением, используя следующую шкалу:

0 - Полностью не согласен

1 - Не согласен

2 - Скорее не согласен

3 - Скорее согласен

4 - Согласен

5 - Полностью согласен

1. Без женской любви даже очень успешный мужчина не может считаться полноценной личностью

2. За стремлением к «равенству» на самом деле скрывается желание многих женщин получить преимущества перед мужчинами (например, при приеме на работу).

3. Большинство женщин воспринимают невинные замечания или действия как оскорбительные.

4. Женщины должны быть окружены заботой и защитой мужчин.

5. Большинство женщин не могут в полной мере оценить все, что мужчины делают для них.

6. Женщины стремятся заполучить власть, устанавливая контроль над мужчинами.

7. У каждого мужчины должна быть женщина, которую он обожает.

8. Без женщины жизнь мужчины нельзя назвать полноценной.

9. Женщины преувеличивают проблемы, с которыми они сталкиваются на работе.

10. Когда женщины проигрывают мужчинам в честном соревновании, они, как правило, жалуются на дискриминацию.

11. Мужчины должны возводить настоящих женщин на пьедестал.

12. Мужчина должен быть готов пожертвовать собственным благополучием для того, чтобы финансово обеспечить женщину.

Враждебный сексизм: 2, 3, 5, 6, 9, 10.

Доброжелательный сексизм: 1, 4, 7, 8, 11, 12.

Агадуллина Елена Рафиковна - доцент, департамент психологии, факультет социальных наук, Национальный исследовательский университет «Высшая школа экономики», кандидат психологических наук.

Сфера научных интересов: психология социального познания, обыденные верования.

Контакты: eagadullina@hse.ru 


\title{
Sexism towards Women: Adaptation of the Ambivalent Sexism Scale (P. Glick and S. Fisk) on a Russian Sample
}

\author{
E.R. Agadullina ${ }^{a}$ \\ ${ }^{a}$ National Research University Higher School of Economics, 20 Myasnitskaya Str., Moscow, 101000, \\ Russian Federation
}

\begin{abstract}
The article presents the Russian adaptation of the Ambivalent Sexism Scale by P. Glick and S. Fisk. This tool measures not only hostile (a tendency to negatively appraise women that violate traditional gender roles), but also benevolent (a tendency to positively appraise women, who comply with the traditional gender roles) sexism. In the approbation of the scale 1624 Russian citizens took part. The full version of the scale demonstrated satisfactory fit to the empirical data, due to more covariance between the items. On the basis of the found covariance between the items, a short version was formed. The short version of the scale comprised 12 items (6 for the subscale of the hostile sexism and 6 for the subscale of the benevolent sexism), it demonstrated a good fit to the empirical data $\left(\chi^{2}=332.147, \mathrm{df}=53, \mathrm{RMSEA}=.057, \mathrm{CFI}=.960, \mathrm{TLI}=.950\right)$ Multigroup analysis demonstrated full structural and factorial equivalence with the use of the short version of the scale on the sample of men and women, as well as heterosexuals and people with non-heterosexual identification. Social-demographical differences were found with the use of the short version of the scale. Men and heterosexuals in a stronger degree, than women and non-heterosexuals, demonstrate hostile and benevolent sexism, people older than 30 in a stronger degree show benevolent sexism, than younger respondents. In the whole the presented variant of the short version of the scale demonstrates good psychometric indices and can be used for further studies as a reliable and valid instrument.
\end{abstract}

Keywords: sexism, hostile sexism, benevolent sexism, scale.

\section{References}

Altemeyer, B. (2006). The Authoritarians. Retrieved from http://members.shaw.ca/jeanaltemeyer/ drbob/TheAuthoritarians.pdf

Bendixen, M., \& Kennair, L. E. O. (2017). When less is more: Psychometric properties of Norwegian short-forms of the Ambivalent Sexism Scales (ASI and AMI) and the Illinois Rape Myth Acceptance (IRMA) Scale. Scandinavian Joumal of Psychology, 58(6), 541-550. doi:10.1111/sjop.12392

Chapleau, K. M., Oswald, D. L., \& Russell, B. L. (2007). How ambivalent sexism toward women and men support rape myth acceptance. Sex Roles, 57(1-2), 131-136. doi:10.1007/s11199-007-9196-2

Christopher, A. N., \& Mull, M. S. (2006). Conservative ideology and ambivalent sexism. Psychology of Women Quarterly, 30(2), 223-230. doi:10.1111/j.1471-6402.2006.00284.x 
Costa, P. A., Oliveira, R., Pereira, H., \& Leal, I. (2015). Adaptation of the Modern Sexism Inventories to Portugal: The Ambivalent Sexism Inventory and the Ambivalence toward Men Inventory. Psicologia: Reflexão e Crítica, 28(1), 126-135.

Dardenne, B., Delacollette, N., Grégoire, C., \& Lecocq, D. (2006). Structure latente et validation de la version française de l'Ambivalent Sexism Inventory: l'échelle de sexisme ambivalent [Latent structure and validation of the French version of the Ambivalent Sexism Inventory: the ambivalent sexism scale]. Lannée Psychologique, 106, 235-264. (in French)

Eckes, T., \& Six-Materna, I. (1999). Hostilitдt und Benevolenz: Eine Skala zur Erfassung des ambivalenten Sexismus [Hostility and benevolence: A scale measuring ambivalent sexism]. Zeitschrift für Sozialpsychologie, 30, 211-228. (in German)

Forbes, G. B., Collinsworth, L. L., Jobe, R. L., Braun, K. D., \& Wise, L. M. (2007). Sexism, hostility toward women, and endorsement of beauty ideals and practices: Are beauty ideals associated with oppressive beliefs? Sex Roles, 56(5-6), 265-273. doi:10.1007/s11199-006-9161-5

Garaigordobil, M., \& Aliri, J. (2013). Ambivalent sexism inventory: Standardization and normative data in a sample of the Basque country. Behavioral Psychology / Psicología Conductual, 21(1), $173-186$.

Gaunt, R. (2013). Breadwinning moms, caregiving dads: Double standard in social judgments of gender norm violators. Joumal of Family Issues, 34(1), 3-24. doi:10.1177/0192513X12438686

Glick, P., \& Fiske, S. T. (1996). The Ambivalent Sexism Inventory: Differentiating hostile and benevolent sexism. Joumal of Personality and Social Psychology, 70(3), 491-512. doi:10.1037/00223514.70.3.491

Glick, P., \& Fiske, S. T. (2001). An ambivalent alliance. Hostile and benevolent sexism as complementary jutifications for gender inequality. American Psychologist, 56(2), 109-118. doi:10.1037/0003066X.56.2.109

Glick, P., Fiske, S. T., Masser, B., Manganelli, A. M., Huang, L. L., Rodríguez Castro, Y., ... Wells, R. (2004). Bad but bold: Ambivalent attitudes toward men predict gender inequality in 16 nations. Journal of Personality and Social Psychology, 86(5), 713-728. doi:10.1037/0022-3514.86.5.713

Glick, P., Fiske, S. T., Mladinic, A., Saiz, J. L., Abrams, D., Masser, B., ... López, W. L. (2000). Beyond prejudice as simple antipathy: Hostile and benevolent sexism across cultures. Joumal of Personality and Social Psychology, 79(5), 763-775. doi:10.1037/0022-3514.79.5.763

Glick, P., Sakall -Ugurlu, N., Ferreira, M. C., \& Aguiar de Souza, M. (2002). Ambivalent sexism and attitudes toward wife abuse in Turkey and Brazil. Psychology of Women Qharterly, 26(4), 292-297. doi:10.1111/1471-6402.t01-1-00068

Glick, P., \& Whitehead, J. (2010). Hostility toward men and the perceived stability of male dominance. Social Psychology, 41(3), 177-185. doi:10.1027/1864-9335/a000025

Glick, P., Wilkerson, M., \& Cuffe, M. (2015). Masculine identity, ambivalent sexism, and attitudes toward gender subtypes: Favoring masculine men and feminine women. Social Psychology, 46(4), 210-217. doi:10.1027/1864-9335/a000228

Goncalves, G., Orgambidez-Ramos, A., Giger, J.-C., Santos, J., \& Gomes, A. (2015). Validity evidence of the Portuguese adaptation of the Ambivalent Sexism Inventory. Revista de Psicología Social, 30(1), 152-181.

Hu, L., \& Bentler, P. M. (1999). Cutoff criteria for fit indexes in covariance structure analysis: Conventional criteria versus new alternatives. Structural Equation Modeling: A Multidisciplinany Joumal, 6(1), 1-55. doi:10.1080/10705519909540118 
Ibabe, I., Arnoso, A., \& Elgorriaga, E. (2016). Ambivalent Sexism Inventory: Adaptation to Basque population and sexism as a risk factor of dating violence. Spanish Joumal of Psychology, 19(2016), 1-9. doi:10.1017/sjp.2016.80

Jost, J. T., Banaji, M. R., \& Nosek, B. A. (2004). A decade of system justification theory: Accumulated evidence of conscious and unconscious bolstering of the Status Quo John. Political Psychology, 25(6), 881-919. doi:10.1111/j.1467-9221.2004.00402.x

Mosso, C., Briante, G., Aiello, A., \& Russo, S. (2013). The role of legitimizing ideologies as predictors of ambivalent sexism in young people: Evidence from Italy and the USA. Social Justice Research, 26(1), 1-17. doi:10.1007/s11211-012-0172-9

Pratto, F., Sidanius, J., Stallworth, L. M., \& Malle, B. F. (1994). Social dominance orientation: A personality variable predicting social and political attitudes. Joumal of Personality and Social Psychology, 67(4), 741-763. doi:10.1037/0022-3514.67.4.741

Rollero, C., Glick, P., \& Tartaglia, S. (2014). Psychometric properties of short versions of the Ambivalent Sexism Inventory and Ambivalence Toward Men Inventory. TPM - Testing, Psychometrics, 'Methodology in Applied Psychology, 21(2), 149-159. doi:10.4473/TPM21.2.3

Russell, B. L., \& Trigg, K. Y. (2004). Tolerance of sexual harassment : An examination of gender differences, ambivalent sexism, social dominance, and gender roles. Sex Roles, 50(7-8), 565-573.

Sakalli-Ugurlu, N. (2002). Çelişik duygulu cinsiyetçilik ölçeği: Geçerlik ve güvenirlik çalışması. [Ambivalent Sexism Inventory: A Study of Reliability and Validity]. Türk Psikoloji Dergisi, 17(49), 47-58. (in Turkish)

Sutton, R. M., Douglas, K. M., \& McClellan, L. M. (2011). Benevolent sexism, perceived health risks, and the inclination to restrict pregnant women's freedoms. Sex Roles, 65(7), 596-605. doi:10.1007/s11199-010-9869-0

Thompson, E. P., \& Jost, J. T. (2000). Group-based dominance and opposition to equality as independent predictors of self-esteem, ethnocentrism, and social policy attitudes among African Americans and European Americans. Journal of Experimental Social Psychology, 36(3), 209-232. doi:10.10061999.1403

Viki, T. G., Abrams, D., \& Hutchison, P. (2003). The "true" romantic: Benevolent sexism and paternalistic chivalry. Sex Roles, 49, 533-537.

Zawisza, M., Luyt, R., \& Zawadzka, A. M. (2015). Societies in transition: are they more sexist? A comparison between Polish, South African and British samples.Journal of Gender Studies, 24(1), 38-55. doi:10.1080/09589236.2013.803952

Elena R. Agadullina - associate professor, Faculty of Social Sciences, School of Psychology, National Research University Higher School of Economics, Ph.D.

Research area: social cognition, implicit theories, lay theories.

E-mail: eagadullina@hse.ru 